\title{
Microsurgical ressection for parasagittal meningiomas with preservation of the parasagittal sinus and excelent neurovascular control
}

\author{
Ressecção microcirúrgica dos meningiomas parasagitais com excelente controle vascular \\ e preservação do seio longitudinal superior \\ José Carlos Lynch', Hugo Schiavini², Cleber Bomfim², Joelton Fernandes Fonseca², Celestino Pereira ${ }^{3}$
}

\begin{abstract}
Objective: It was to observe whether a microsurgical gross total removal (GTR) of a parasagittal meningioma (PSM) outside the sinus is a safe and efficient procedure. Method: We identify 58 parasagittal meningiomas patients. Medical charts, operative reports, imaging studies and clinical follow-up evaluations were reviewed. Results: GTR of the mass was achieved in 45 (77.7\%) instances. The surgical mortality rate was $1.7 \%$. The median follow-up time was 63 months. Conclusion: The surgical approach used in this group of patients afford that the great majority of tumors could be totally removed with low mortality, proving to be safe and effective.
\end{abstract}

Key words: brain neoplasms, craniotomy, meningioma, microsurgery, outcome, surgical treatment.

RESUMO

Objetivo: Foi observar se a ressecção microcirúrgica extrassinusal dos meningiomas parasagitais é uma técnica segura e efetiva. Método: Foram estudados 58 pacientes portadores de meningiomas parasagitais. Quadros médicos, relatórios de operações, exames de imagem e seguimento clínico foram revisados. Resultados: A remoção total da lesão, fora do seio, ocorreu em 45 casos (77,7\%). A taxa de mortalidade cirúrgica observada nesta série foi de 1,7\%. 0 tempo médio de seguimento foi de 63 meses. Conclusão: A estratégia microcirúrgica empregada propiciou a remoção total dos meningiomas na maioria dos pacientes, com baixa mortalidade e morbidade, mostrando ser segura e efetiva.

Palavras-Chave: neoplasias encefálicas, craniotomia, meningioma, microcirurgia, resultado, tratamento cirúrgico.

The term parasagittal implies that tumor arising from the duramater on the convexity of the hemisphere involves the walls and possibly the lumen of the sagittal sinus ${ }^{1}$. The parasagittal meningioma (PSM) is a subgroup of meningiomas comprising from 19.5 to $45 \%$ of all intracranial meningio$\mathrm{mas}^{2,3}$. The propensity for these tumors to invade or even encase the superior sagittal sinus (SSS) and adhere to the bridge cerebral veins can greatly complicate the efforts to achieve a safe and gross total removal (GTR) of the tumors and its involved dural base ${ }^{1,3-20}$.

Cushing $^{2}$, in 1910, operated the first patient for a PSM. The pioneer works of Hoessly and Olivercrona ${ }^{3}$, Poppen ${ }^{4}$, Logue $^{5}$ and others paved the away for contemporary neurosurgery techniques in dealing with this complex lesion ${ }^{6,8-20}$.
The objective of this study was to demonstrate the nuances of our micro surgical technique and analyze the effectiveness of this approach to treat 58 PSM patients.

\section{METHODS}

\section{Data collection}

All the 58 patients with PSM operated on by the senior author between 1981 and 2010 were registered in this retrospective study. The medical charts, pre and postoperative imagings, and pathological reports were retrospectively reviewed for each patient to confirm the diagnosis of a parasagittal meningioma, creating a database from which information pertinent

Study carried out at Neurosurgical Department, Servidores do Estado Hospital, Rio de Janeiro RJ, Brazil.

${ }^{1}$ Head of the Neurosurgical Department, Servidores do Estado Hospital, Rio de Janeiro RJ, Brazil;

${ }^{2}$ Resident, Neurosurgical Department, Servidores do Estado Hospital, Rio de Janeiro RJ, Brazil;

${ }^{3}$ Neurosurgeon, Servidores do Estado Hospital, Rio de Janeiro RJ, Brazil.

Correspondence: José Carlos Lynch; Rua Jardim Botânico 600 / sala 605; 22461-000 Rio de Janeiro RJ - Brasil; E-mail: cneuroamericas@uol.com.br

Conflict of interest: There is no conflict of interest to declare.

Received 12 July 2012; Received in final form 13 December 2012; Accepted 20 December 2012. 
to the present study was collected. The intraoperative videos of 42 patients were analyzed for nuances of the microsurgical technique. The need for informed consent was waived due to the retrospective character of the study. We classified the tumor relationship between the meningioma and the SSS, as described by Sindou and Alvernia ${ }^{9}$. In each case, the Simpson ${ }^{20}$ grade was determined using a combination of the surgeon's assessment with postoperative images. Pathological review was performed based on the WHO guidelines.

\section{Follow-up}

The follow-up varied from 1 to 21.5 years (mean, 5.3 years). The clinic first visit is about 15 days after hospital discharge and then at 2 and 6 months, and after that at oneyear interval. Patients alive were contacted for imaging and clinic visits or at least interviewed by telephone when they described their symptoms referring to brain tumor. The Glasgow Outcome Scale (GOS) defined the outcome. The survival and recurrence-free survival (RFS) was estimated by the Kaplan-Meier method.

\section{Imaging}

All patients were investigated with contrast computed tomography scans in the immediate postoperative period and in the majority of the cases with magnetic resonance image (MRI) at 3 and 12 months and intermittently there after.

\section{Surgical technique}

In all cases, the same microsurgery technique was used, following these general steps:

Position - under endotracheal general anesthesia, the patient's head is secured in the Mayfield three-point fixation system. Due to risk of air embolism, a central venous catheter was placed in all patients to allow air aspiration, if necessary. In case of tumors located in the anterior third of SSS, the patient is positioned supine, with 30 degrees elevation. In patients with tumors involving the middle third, we have preferred the lateral decubitus position with the tumor side inferior, so that gravity causes the brain to fall away from the tumor, decreasing the use of brain retraction (Fig 1C). For those lesions located in the posterior third of SSS, we prefer the semi-sitting position. Routine antibiotics, dexamethasone, antiseizure prophylaxis and Manitol were routinely used.

Craniotomy - the skin flap and craniotomy extended to the midline to unilateral tumors and cross to the opposite side, exposing completely the SSS for bilateral tumors (Fig 1C). The bone cutting that crosses the SSS should be the last one to be done, because, in case of sinus laceration, the bone flap can be quickly elevated and the SSS laceration fixed. The operative microscope is introduced in the field and the rest of the procedure is done with magnification that varies from to 10 to $16 \mathrm{x}$.

Opening the dura - the dura is opened parallel and inferior to the midline to a point anterior to the forward, just over the tumor. The opening is then carried to the midline. Finally,
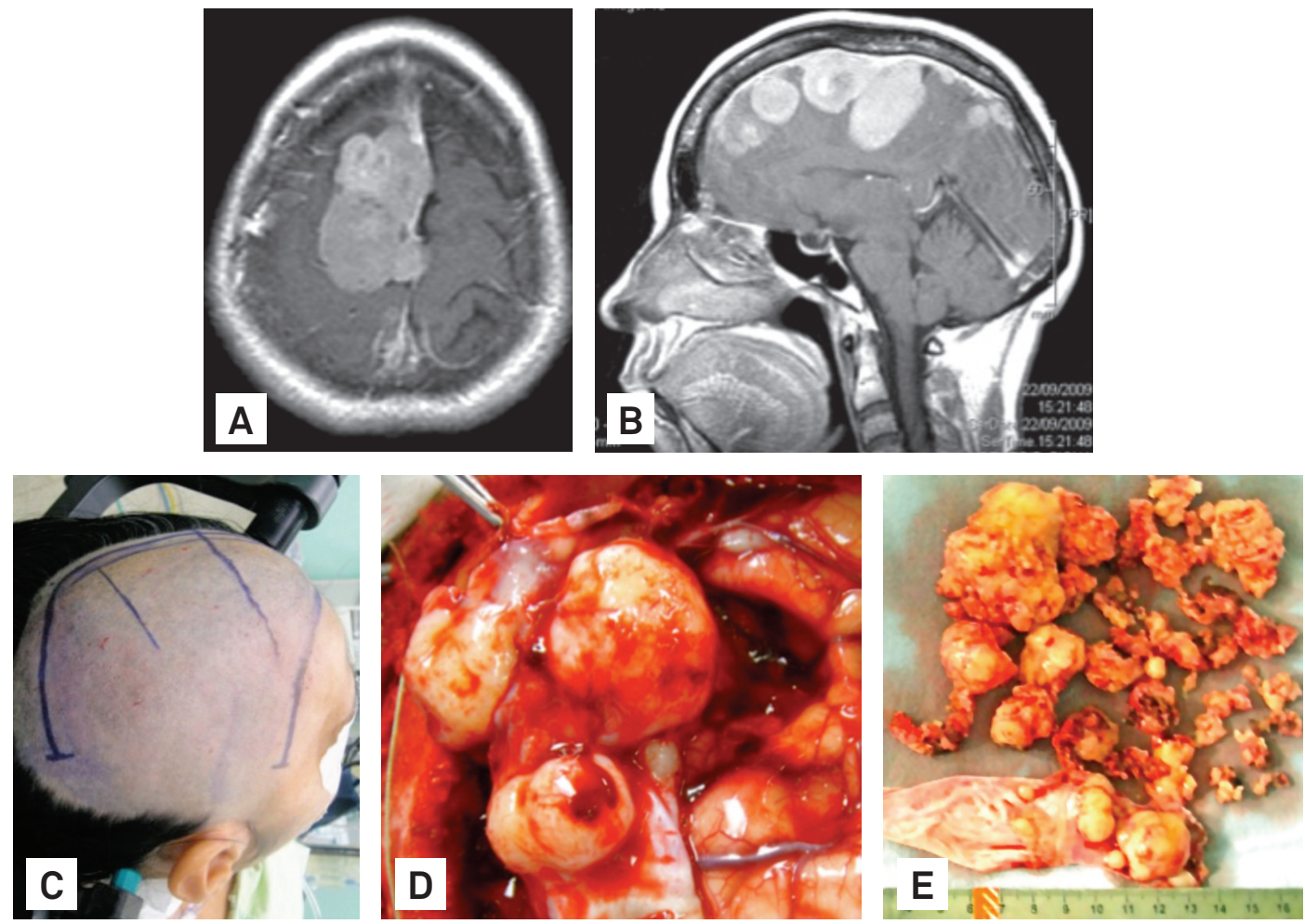

Fig 1. This 54-year-old woman presented headache, progressive hemiparesis, dysarthria and cognitive impairment. (A) Axial T1 Magnetic Resonance Imaging (MRI) showing a large parasagittal meningioma. (B) Sagittal T1 MRI revealing a parasagittal meningioma and several satellites nodules. (C) Operative position, the scalp incision crossing the midline. The tumor side is inferior. (D) Intraoperative view showing several tumor nodules attached to the Falx and superior sagittal sinus. (E) The operative specimen removed in a piece meal fashion. 
the posterior limb of the dural opening is developed in a curvilinear fashion to the midline. The dural flap is reflected medially. It is important to avoid injury to cortical draining veins. The flap is held with temporary traction sutures, which should aid in controlling any ooze from the region of the SSS, an area already covered with strips of hemostatic material. If the tumor is attached to the inner face of the dural flap, a plane of cleavage between the body of the tumor and the internal surface of the dura is developed with a sharp dissection.

Debulking - after bipolar coagulation, the tumor capsule was incised, penetrated and progressively debulked from within, with piece meal tissue removal techniques (Fig 1E). Rigorous homeostasis is maintained throughout the operation. A careful attention was paid to identify and respect the arachnoid plane at the tumor brain interface, which facilitates complete tumor resection and minimizes pial vessel and cortex injury. Only small meningiomas were removed in a single piece (Fig 2C).

Dissecting the tumor - by progressive reduction of the tumor size, the tumor capsule can be gently folded into the central portion of the wound and traction always being applied to the tumor rather than the surrounding brain. The arterioles, veins and arterialized veins located between brain surface and the meningioma are bipolar coagulated, under saline irrigation, and sectioned with micro scissors, to interrupt the vascular supply to the tumor in order to devascularize the meningioma and minimize intraoperative bleeding, and a carefully dissection is necessary to preserve en passant vessels. Once an area of cleavage between the tumor and brain has been developed, this should be protected with a successive series of wet cotton strips, which are placed circumferentially, and mobilized toward the deep planes and left untouched until the end of the surgery.

Veins and arteries - it is essential to preserve the afferent bridging veins to the SSS; especially the ones in the middle-third portion of the sinus and care should be taken to avoid excessive traction on theses structures. We did not resect patent cortical bridging veins involved with tumor, we preferred to leave tumor remnants that are densely adherent to these vessels.

The pericallosal and callomarginal arteries should be identified in the inferior-medial aspect of the mass, and spared. When removing the tumor from the pericallosal and callomarginal arteries, gentle sharp dissection and low power coagulation should be used to avoid arterial damage. The feeding branches from these arteries to the tumor are identified, isolated, bipolar coagulated and sectioned. Tumor adherent to the falx below the SSS can usually be swept off with a micro dissector, leaving a smooth, clearly uninvolved surface.

Superior sagittal sinus - the tumor attached to one wall SSS without significant invasion is carefully peeled away from the sinus wall. Venous bleeding from the sinus is controlled with bipolar coagulation under saline irrigation, homeostatic agents and fibrin glue. We did not attempt removal tumor invasion of a patent sinus and, instead, left this portion of the tumor. In patients with complete SSS obliteration, the SSS was ligated at the proximal and distal ends of the involved sinus and then ressected, allowing en bloc tumor removal. Care should be taken to spare any patent cortical bridging veins on the edges of the occluded portion of the sinus (Fig 2C). Before closure, the patient's blood pressure must be brought to a normotensive level for at least 10 to $15 \mathrm{~min}$ utes, and the tumor bed observed for oozing. The involved dura should be ressected with at least to $2-3 \mathrm{~cm}$ circumferential margin or be complete removed. The dura was closed with either a free pericranial graft or the artificial dural substitute. For lesions with invasion, the craniectomy site was repaired using a titanium plate.

Postoperatively - all patients were stayed for at least one day in an intensive care unit before returning to the ward.

\section{Illustrative cases}

Case 1 - a 54-year-old woman presented headache associated with progressive hemiparesis, dysarthria and cognitive impairment. MRI showed a large multilobular tumor located
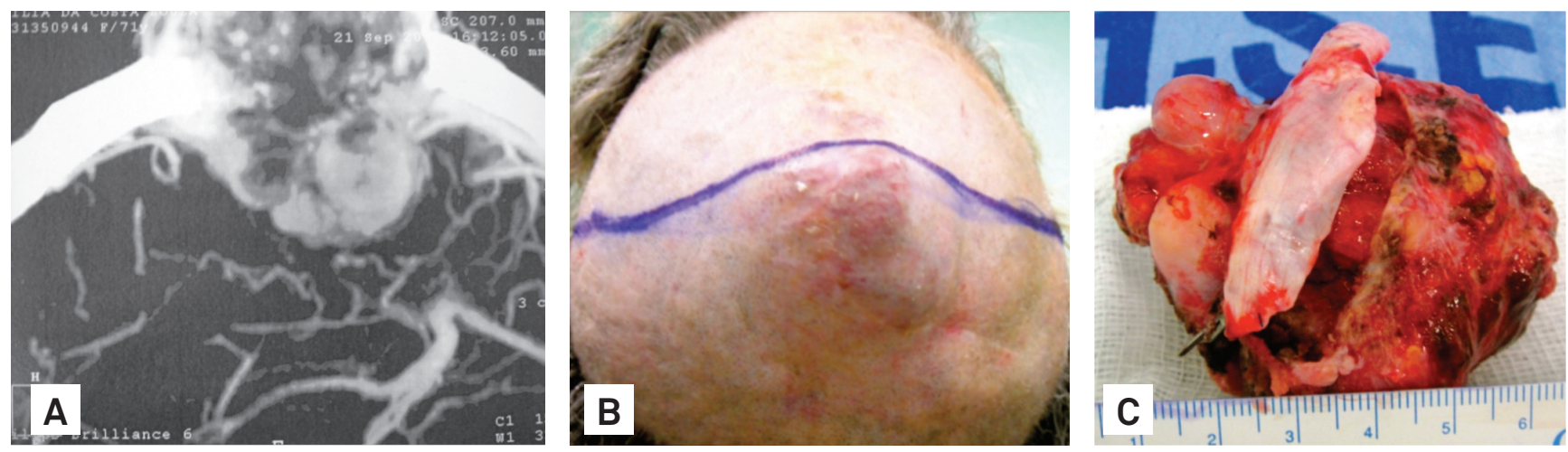

Fig 2. This patient, a 59-year old woman, noticed a tender lump on the top of her head. The neurological exam was normal. (A) Angio computed tomography (CT) showing calvaria erosion and superior sagittal sinus occlusion. (B) Operative view confirming deformation and calvaria erosion. (C) The meningioma removed with the occluded superior sagittal sinus. 
at the left parasagittal region (Figs 1A and B). Gross total resection of the tumor was achieved (Figs 1D and E).

Case 2 - a 59-year old woman noticed a tender lump on the top of her head (Fig 2B). The neurological exam was otherwise normal. Angio CT showed a large tumor that occluded the SSS and eroded the skull (Fig 2A). At surgery, the mass was completely removed together with the occluded SSS (Fig 2C).

\section{RESULTS}

Because this is a retrospective study, it has inherent biases and drawbacks that we believe only a multicenter, prospective study can overcome.

In this series, there were $53(60.3 \%)$ females; range in age from 24 to 84 years (mean 57.4 years). The median follow-up time was 5.3 years (range, 1 to 21.5 years). Seizures, headache and cognitive alteration were the predominant presenting symptoms; hemiparesis was the most common clinical sign (Table 1).

\section{Tumor volume}

The tumor volume was measured utilizing the modi-

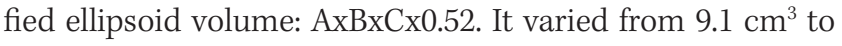
$520 \mathrm{~cm}^{3}$ (mean of $99.3 \mathrm{~cm}^{3}$ ). We considered PSMs $<33.2 \mathrm{~cm}^{3}$ as small. Medium size varies between 33.2 to $112 \mathrm{~cm}^{3}$ and is considered large when it measures $>112.3 \mathrm{~cm}$. Thirteen tumors (22.4\%) were small, 24 (41.3\%) were medium-sized and 21 were large $(36.2 \%)$ (Table 1$)$.

\section{Relationship between the tumor and SSS}

Type 1 tumor, as defined by Sindou and Alvernia ${ }^{9}$ as a lesion that attached to the outer surface of the sinus wall, was found in $32(55.1 \%)$ patients; type 2 tumor, fragment inside the lateral recession, was detected in 12 (20\%) occasions; type 3, invasion of the ipsilateral wall, was observed in $6(10.4 \%)$ cases; type IV, invasion of the lateral wall and roof, was reported in $4(6.8 \%)$ situations; type 5 , a complete sinus occlusion, was observed in $4(6.8 \%)$ individuals.

\section{Histological features}

The pathology, as defined by the OMS for the classification of mengiomas, was benign in 48 cases (82.7\%), atypical in $7(12.2 \%)$ and malignant in 3 patients $(5.1 \%)$.

\section{Mortality and clinical outcome}

The operative mortality in this series was $1.7 \%$ (one patient). During this period, seven individuals died: three deaths were not related to the tumor, and four were due to progression of tumor or recurrence. The overall mortality of this series was $12 \%$. At the time of the last follow-up, 28 patients were in GOS 5, 8 in GOS 4, 6 in GOS 3 and 4 in GOS 2. Excellent or good outcome was achieved in 41 patients of this sample, $80.2 \%$ of cases. Five patients were lost during follow-up.

\section{Resection extend and recurrence}

A gross-total removal of the mass outside the sinus with outer layer peeling associated with coagulation of the inner layer of the sinus was obtained in $45(77.7 \%)$ patients (Figs $3 \mathrm{~A}$ and B). In four cases, the sinus was completely occluded and it was resected with tumor inside (Fig 2C). The recurrence rate was observed in seven occasions (12\%). The five-year survival estimates were $86.3 \%$.

\section{DISCUSSION}

Nowadays, there are two main accepted surgical strategies to treat these lesions: resection of the tumor mass outside the sinus wall(s) and coagulation of the remnant $^{3-6,10,12,14,15}$ or aggressive resection of tumors inside of the SSS and venous reconstruction ${ }^{8,9,16-19}$. The optimal management is subject to controversy.

Black et al. ${ }^{6,12}$, Sughrue et al. ${ }^{15}$, and DiMeco et al. ${ }^{10}$ recommended removal of as much tumor as possible while leaving tumor remnants that significantly involve the sinus. If tumor progresses, they recommend fractionated radiotherapy. Their data suggest that small residual portions of WHO Grade I tumors left in and around the SSS generally do not grow appreciably. The same surgical technique is followed by Colli et al. ${ }^{11}$.

On the other hand, Raza et al. ${ }^{7}$, Pradilla et al. ${ }^{8}$ and Bonnal and Brotchi ${ }^{17}$ declared that for type III and IV tumors with demonstrated sinus flow, the sinus was entered to resect the tumor and the was reconstructed.

Sindou and Alverni ${ }^{9,12}$ have reported an aggressive resection of tumors inside the SSS and venous reconstruction of

Table 1. Characteristics of 58 patients treated with parasagittal meningiomas.

\begin{tabular}{lc}
\hline Age at treatment & 24 to 84 years (mean 57.4 years) \\
Female & $35(60.34 \%)$ \\
Male & $23(39.6 \%)$ \\
Multiple meningiomas & $5(8.6 \%)$ \\
Clinical-neurological picture: & \\
$\quad$ Motor deficit & $39(69.6 \%)$ \\
Seizures & $21(37.5 \%)$ \\
Headache & $17(30.35 \%)$ \\
Mental deficit & $12(21.4 \%)$ \\
Volume & 9.1 to $520 \mathrm{~cm}^{3}\left(\right.$ mean of $\left.99.3 \mathrm{~cm}^{3}\right)$ \\
Grade (OMS): & \\
Grade 1 & $48(82.7 \%)$ \\
Grade 2 & $7(12.6 \%)$ \\
Grade 3 & $3(5.1 \%)$ \\
Follow-up & 1 to 21.5 years (mean, \\
Patients lost to follow-up & 5.3 years) \\
Surgical mortality & $7(12 \%)$ \\
Recurrence & $1(1.7 \%)$ \\
Gross total removal & $7(12 \%)$ \\
\hline
\end{tabular}



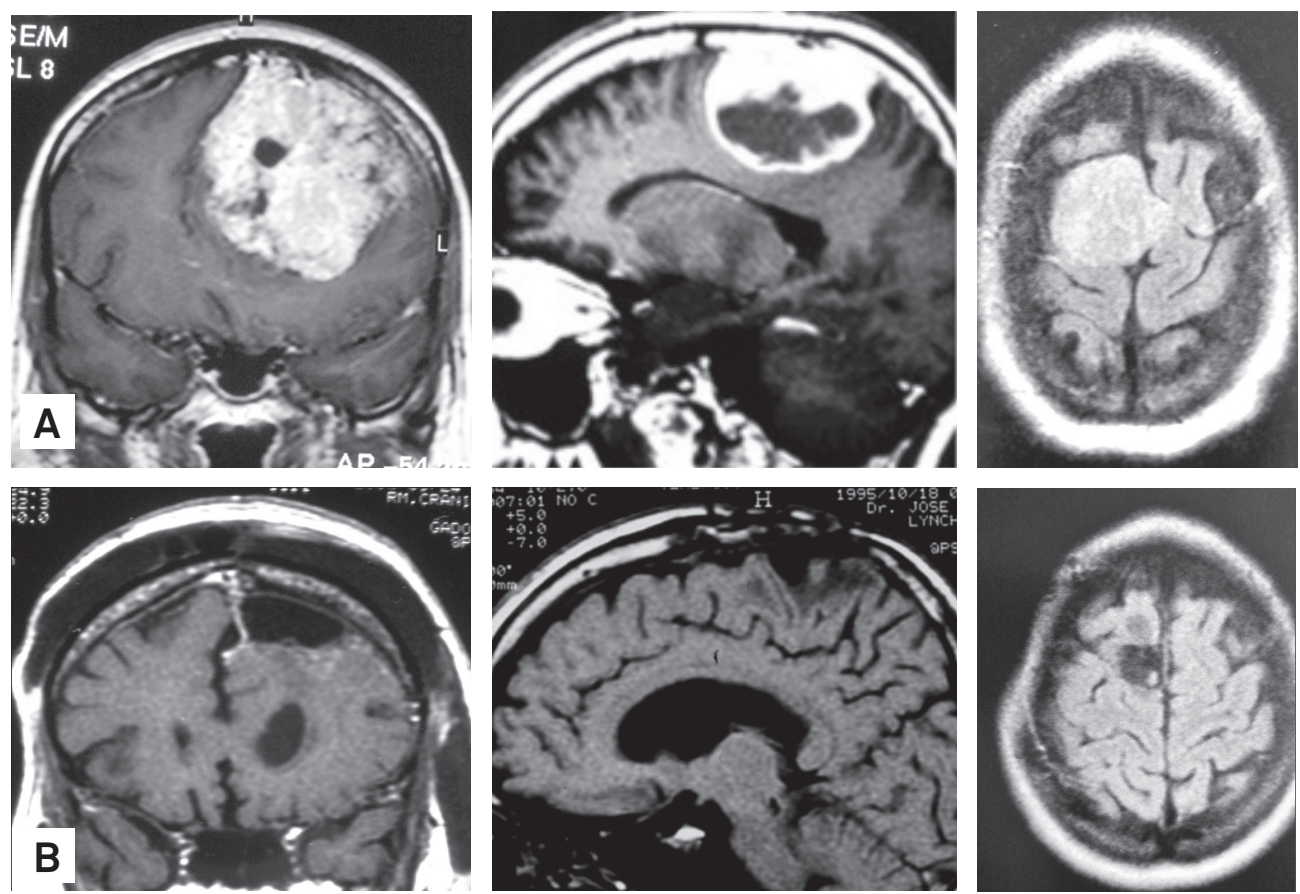

Fig 3. Some examples of small, medium and large tumors with gross total removal. (A) Preoperative. (B) Postoperative.

the sinus with autologus vein or periosteum graft. They concluded that relatively low mortality and recurrence rate favor attempting at complete tumor removal, including the portion invading the sinus.

Surgical mortality in PSM has been described in the literature, varying from $45 \%$ in the first published series to $1.5 \%$ in the most contemporary ones. Tumor recurrence rates have varied from 4 to $32.7 \%$ during a 4.4 to 13-year follow-up ${ }^{18}$ (Table 2).

Our department's elected procedure is to perform surgery aiming at total exeresis of the meningiomas and of their dural implants, but not removing tumor inside the sinus. We achieved a surgical mortality rate of $1.7 \%$ and a recurrence rate of $12 \%$ during a 5.3-year follow-up.

Although the resection of the tumor inside of the sinus leads to a possible lower rate of recurrence, it increases the risk of hemorrhage, SSS thrombosis or venous infarction leading to edema and neurologic deteriolization. Otherwise, tumors involving a partially patent sinus can be subtotally resected, and the remnants can be followed or treated with repeated surgery or radio surgery $y^{5,612,15,16,18}$. Those procedures are being increasingly used in the treatment of meningiomas in risky locations $\mathbf{s}^{21,22}$.
Table 2. Surgical series on parasagittal meningiomas.

\begin{tabular}{|c|c|c|c|c|}
\hline Author/year & $\begin{array}{c}n \\
\text { cases }\end{array}$ & $\begin{array}{l}\text { Mort. } \\
(\%)\end{array}$ & $\begin{array}{l}\text { Rec. } \\
(\%)\end{array}$ & $\begin{array}{c}F / U \\
\text { (years) }\end{array}$ \\
\hline $\begin{array}{l}\text { Hoessly and } \\
\text { Olivecrona }{ }^{3 / 1953}\end{array}$ & 196 & 12.3 & 6 & 5 \\
\hline Simpson²0/1957 & 107 & - & 19 & 5 \\
\hline Logue $^{5 / 1975}$ & 91 & 4.4 & 11 & - \\
\hline $\begin{array}{l}\text { Bonnal and } \\
\text { Brotchi }{ }^{17 / 1978}\end{array}$ & 21 & 4.7 & 14 & - \\
\hline Giombini et al.13/1984 & 243 & - & 17.7 & 5 \\
\hline Dimeco et al.10/2008 & 108 & 1.9 & 13.9 & 6.6 \\
\hline $\begin{array}{l}\text { Sindou and } \\
\text { Alvernia } 9 / 2000\end{array}$ & 100 & 3 & 4 & 8 \\
\hline Colli et al.11/2006 & 53 & 1.9 & 32.7 & 7.8 \\
\hline Raza et al.?/2010 & 61 & 1.5 & 11 & 4.4 \\
\hline Current series & 58 & 1.7 & 12 & 5.3 \\
\hline
\end{tabular}

Mort: mortality; Rec: Recurrence; F/U: folow-up.

We can conclude that the approach used for this group of patients, which consisted of a less aggressive resection in cases of tumor invasion of a patent SSS, allowed excellent neurovascular control and resection of most of the tumor tissues, and proved to be safe and very effective. The residual tumor in the event of subsequent growth can be treated with radiosurgery or repeated surgery.

\section{References}

1. Maxwell RE, Chou SN. Parasagittal and falx meningioma. Operative neurosurgery. In: Schmidek HH, Sweet WH (Eds). $2^{\text {nd }}$ edition. Orlando: Grune Stratton; 1988 p. 563-570.

2. Cushing $\mathrm{H}$. Meningiomas their classification regional behavior. Life history and surgical end results. Springfield 1938:404-505.

3. Hoessly F, Olivecrona H. Report on 280 cases of verified parasagittal Meningioma.J Neurosurg 1955;12:614-626.
4. Poppen JL. An atlas of neurosurgical techniques. Philadelphia: WB Saunders; 1960. p. 99-105.

5. Logue V. Parasagittal meningiomas. Advances and technical standards in neurosurgery. In: Krayenbull H (Ed). New York: Springer; 1975. p. 171-198.

6. Black PM, Zauberman S. Parasagittal and falx meningiomas. Meningiomas: a comprehensive text. In: Palmir MN, Black PM, Fallbusch R (Eds). China: Saunders; 2010. p. 349-354. 
7. Raza SM, Gallia GL, Brem H, Wegart JD, Long DM, Olivi A. Perioperative and long tern outcomes from management of parasagittal meningiomas invading the superior sagittal sinus. Neurosurgery 2010;67:885-893.

8. Pradilla G, Solero CL, Dimeco F. Parasagittal meningiomas. Al-mefty's meningiomas. In: De Monte F, Mc Dermott MW, Al-Mefty O (Eds). New York: Thieme; 2011. p. 142-160.

9. Sindou MP, Alvernia JE. Results of attempted radical tumor removal and venous repair in 100 consecutive meningiomas involving the major dural sinuses. J Neurosurg 2000;105:514-525.

10. DiMeco F, Li KW, Casli C, et al. Meningiomas invading the superior sagittal sinus: surgical experience in 108 cases. Neurosurgery 2008;62;S1124-S1135.

11. Colli BO, Carlotti CG, Assirati JA Jr, Dos Santos MB, Neder L, Dos Santos AC. Parasagital meningiomas: follow-up review. Surg Neurol 2006;66:S520-S527.

12. Black PM, Morokott AP, Zanberman J. Surgery of extra-axial tumors of the cerebral convexity and midline. Neurosurgery 2008;62:1115-1121.

13. Giombini S, Solero CL, Lasio G, Morello G. Immediate and late outcome of operations for parasagittal and falx meningiomas. Report of 342 cases. Surg Neurol 1984;21:427-435.

14. Ransohof J. Parasagittal meningiomas. J Neurosurg 1972;37:372.

15. Sughrue ME, RutkowSki, Gopal SG, et al. Results with judicious modern neurosurgical management of parasagittal and falcine meningiomas.J Neurosurg 2011;114:731-737.
16. Schmid-Elsaesser R, Steiger HJ, Yousry T, Seelos KC, Reulen HJ. Radical resection of meningiomas and arteriovenous fistulas involving critical dural sinus segments: experience with intraoperative sinus pressure monitoring and elective sinus reconstruction in 10 patients. Neurosurgery 1997;41:1005-1016.

17. Bonnal J, Brotchi J. Surgery of the superior sagittal sinus in parasagittal meningiomas. J Neurosurg 1978;48:935-945.

18. Hancq S, Baleriaux D, Brotchi J. Surgical treatment of parasagital meningiomas. Semin Neurosurg 2003;14:203-210.

19. Hakuba A, Huh $\mathrm{CH}$, Tsujikawa S, Nishimura S. Total removal of a parasagittal meningioma of the posterior third of the sagittal sinus and its repair by autogenous vein graft. Case report. J Neurosurg 1978;48:935-945.

20. Simpson D. The recurrence of intracranial meningiomas after surgical treatment. J Neurol Neurosurg Psychial 1957;20:2-39.

21. Kondziolka D, Flickinger JC, Perez B. Judicious resection and/ or radiosurgery for parasagittal meningiomas: outcomes from a multicenter review: Gamma Knife Meningioma Study Group. Neurosurgery 1998;43:405-413.

22. Santacroce A, Walier M, Régis J, et al. Long-term tumor control of benign intracranial meningiomas after radiosurgery in a series of 4565 patients. Neurosurgery 2012;70:32-39. 